\title{
Da gradação ausente à gradação harmônica: Atmosphères de György Ligeti
}

\section{Claudio Vitale}

Resumo: Neste artigo, fazemos uma análise das três primeiras seções (ou campos sonoros) da obra Atmosphères (1961), de György Ligeti. Estudamos a relação entre alturas, os processos de simetria, de gradação, de ilusão, e os planos harmônicos gerados a partir do jogo com a intensidade. Fazemos uma leitura da obra a partir da ideia de gradação. Este conceito, elaborado pelo autor, está embasado em pesquisas desenvolvidas em diversos campos do conhecimento humano, como a retórica, a linguística, a literatura, as artes visuais e a própria música.

Abstract: In this article we make an analysis of the first three sections (or sound fields) of György Ligeti's work Atmosphères (1961). We study the relationship between pitches, the processes of symmetry, gradation, illusion and the harmonic layers generated by intensity changes. We make an interpretation of this work based on the idea of gradation. This concept, developed by the author, is inspired on similar ideas taken from different fields of human knowledge, like Rhetoric, Linguistics, Literature, Visual Arts and Music itself.

O conceito de gradação tem sido utilizado em diversos campos do conhecimento humano. Vejamos, brevemente, alguns exemplos.

Genericamente, a gradação pode ser entendida segundo a clássica definição da retórica que a define como uma figura de linguagem, onde os elementos se encontram ordenados de forma crescente ou decrescente'. Em Filosofia da Composição, Edgar Allan Poe

1 Por exemplo: Dubois (2011), Fontanier (1977), Moisés (2004) e Molinié (1992). 
(1846) utiliza engenhosamente este conceito ao se debruçar na análise do seu poema "O corvo". No artigo Grading: a study in semantics, Edward Sapir estuda o fenômeno da gradação a partir do ponto de vista lógico, psicológico e linguístico. No âmbito do desenho gráfico, a gradação tem um lugar de destaque, pois, como afirma Wong (1995, p. 75): "A gradação é uma experiência visual diária. As coisas que estão perto de nós parecem grandes e as que estão longe parecem pequenas ${ }^{2}$." Logo, o autor acrescenta: "Se olharmos de baixo um prédio alto, com uma fachada de janelas iguais, a mudança em tamanho das janelas sugere uma lei da gradação3". No caso da música, vale lembrar do interesse do compositor Paul Hindemith nas gradações harmônicas ${ }^{4}$. Um trabalho mais recente dirigido pelo compositor e pesquisador argentino Mariano Etkin (2000) traz novamente à tona este conceito. Mais especificamente, trata-se de uma análise da obra Hallowe'en, de Charles Ives, a partir da ideia de "gradualidade" ou "estrutura escalar". Neste artigo, damos continuidade às pesquisas mencionadas anteriormente tomando o conceito de gradação como base para nossas interpretações 5 . Focamos nossa análise nos três primeiros "campos" (seções) da obra Atmosphères (1961), de György Ligeti.

\section{Atmosphères e as gradações texturais mínimas}

Atmosphères é composta por um movimento só. Longe das formas dialéticas constituídas a partir de relações de oposição entre materiais, esta obra é construída a partir da transformação gradual de

\footnotetext{
2 "La gradación es una experiencia visual diaria. Las cosas que están cerca de nosotros parecen grandes, y las lejanas parecen pequeñas" (Wong, 1995, p. 75).

3 "Si miramos desde abajo a un edificio alto, con una fachada de ventanas iguales, el cambio en tamaño de las ventanas sugiere una ley de la gradación" (Wong, 1995, p. 75).

4 Ver: Coelho de Souza (2009) e Hindemith (1970).

5 O conceito de gradação, tal como é utilizado neste artigo, foi elaborado pelo autor a partir das fontes supra citadas (Vitale, 2013).
} 
um único material. Nesse sentido, é possível afirmar que são apenas as modificações texturais as que modelam a forma. Não há divisões claras nem encadeamento dos diferentes estados do material que possa sugerir, na escuta, a presença de um discurso linear ou direcional. "Não se percebem alturas mas texturas, não se percebem ritmos mas irisações da textura. Ligeti não compõe parametricamente, mas põe a funcionar todas as dimensões da escrita em favor de uma textura que muda de tom" (Monjeau, 2004, p. 115) ${ }^{6}$.

\section{Seção I (começo): a gradação ausente?}

Figura 1. Atmosphères, c. 1-8; alturas.

(a)
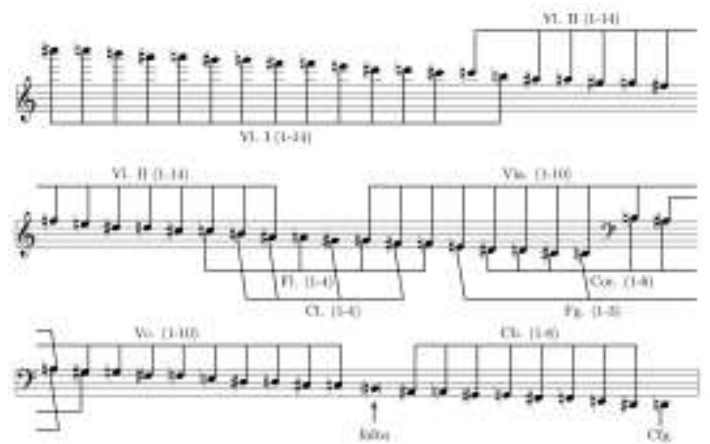

(b)

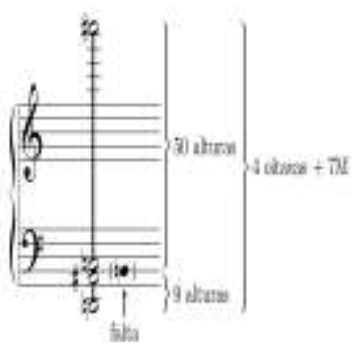

6 "No se perciben alturas sino texturas, no se perciben ritmos sino irisaciones de textura. Ligeti no compone paramétricamente, sino que pone a funcionar todas las dimensiones de la escritura a favor de una textura que cambia de tono" (Monjeau, 2004, p. 115). 
Na Figura 1 mostramos: na parte (a), as alturas que aparecem na primeira seção da obra junto com os instrumentos que as executam e, na parte (b), o cluster resultante.

A partir da Figura 1 podemos comentar os seguintes aspectos. A primeira seção de Atmosphères é formada por um cluster cromático de quase 5 oitavas. O registro, compreendido entre Ré2 e Dó\#7 aparece, com exceção de uma nota ( $\mathrm{Si} 2)$, totalmente preenchido7. Trata-se de um enorme cluster estático formado por uma elevada densidade de vozes (59 alturas), em pianissimo ( $p p$, dolcissimo), orquestrado com instrumentos de sopro (4 flautas, 4 clarinetes, 3 fagotes, 1 contrafagote e 6 trompas) e cordas em divisi, tocando uma nota só por instrumento (14 violinos I, 14 violinos II, 10 violas, 10 violoncelos e 8 contrabaixos) ${ }^{8}$. Como a indicação metronômica é de semínima $=40$, a duração de cada semínima é de 1,5" e a de cada compasso de 4/4 é de 6". A duração da seção (de 8 compassos) é de aproximadamente $48^{\prime \prime}$.

Nesta seção, a evolução do material é realmente ínfima. Embora pouco perceptível, existe uma gradação timbrística ocasionada pela diminuição gradual da intensidade e a posterior subtração de alguns instrumentos. Os diminuendi seguem a seguinte ordem: contrafagote (compassos 2-3), flautas (c. 3-4), fagotes (c. 5-6) e o resto da orquestra no final da seção (c. 7-8). Cada instrumento deixa de tocar depois de fazer o diminuendo. Com a saída do contrafagote, o cluster fica sem a

\footnotetext{
7 Consideramos sempre o Dó central do piano como Dó4.

8 Ligeti explica alguns detalhes sobre a notação da obra que vale a pena mencionar para um melhor seguimento dos exemplos dados neste trabalho. Os clarinetes e trompas estão escritos como soam. Instrumentos transpositores de oitava, como flautim, contrafagote e contrabaixo (inclusive os harmônicos), são escritos sem transposição. Resumindo, todos os sons da partitura são suoni reali, com exceção dos transpositores de oitava que soam na sua habitual transposição.

9 Ligeti indica, na partitura, a duração de cada seção. As indicações metronômicas colocadas na partitura e as respectivas durações de cada seção estão em relação com M.M. 40. No entanto, o compositor indica que a obra pode ser executada mais lenta ajustando, nesse caso, as relações entre todos os tempi.
} 
nota mais grave, Ré2; com a ausência das flautas, outra nota também desaparece do cluster, Lá4. O cluster, portanto, que já tinha um buraco desde o começo (Si2) passa a ter outro (Lá4) e a reduzir seu âmbito intervalar num semitom (pela ausência do Ré2). Vale acrescentar que, por causa da grande massa de som em jogo, estas modificações têm pouco impacto na audição.

\section{Seção II (A): a gradação insinuada}

Figura 2. Atmosphères, seção II (A), c. 9-13, alturas.

(a)

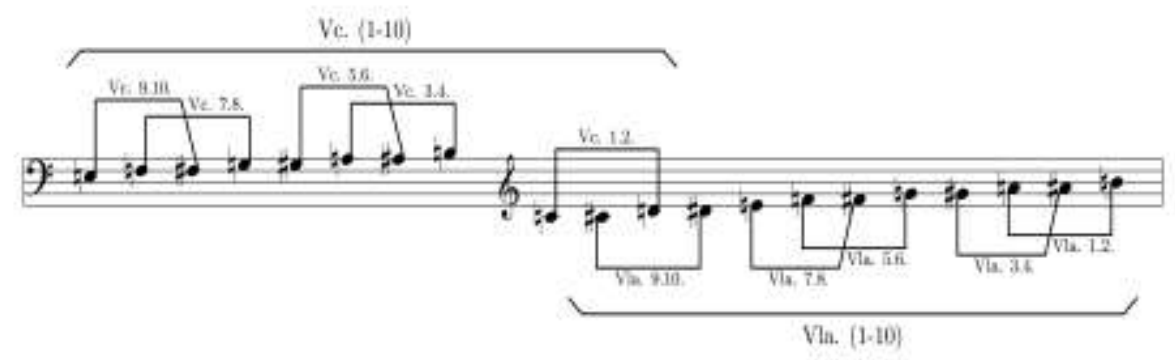

(b)

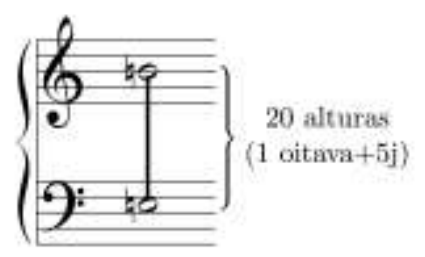

A seção II tem o mesmo valor metronômico que a primeira seção (semínima $=40$ ); abarca os compassos 9-13, tem uma duração de 29" e se desprende da seção anterior. Em relação às alturas, nada mais é do que a parte central do cluster do começo da obra. Este cluster, realizado exclusivamente pelas violas e os violoncelos, vai do Mi3 até o Si4, ocupando 1 oitava +5 justa. Se na seção anterior havia 59 vozes, nesta 
há menos da metade, 20 vozes. Neste sentido, podemos dizer que a seção A é gerada não por adição, mas por subtração de vozes. Veja-se a Figura 2, onde mostramos: na parte de cima (a), as alturas pertencentes à seção II com os instrumentos que as executam, e na parte de baixo (b), o âmbito intervalar do cluster.

Os compassos 11-13 apresentam um trabalho particularmente interessante de camadas em crescendi que antecipa as características fundamentais da seção seguinte. Antes de analisar isto em detalhe vejamos alguns aspectos sobre a figura utilizada.

Figura 3. Atmosphères, c. 11-13, abertura gradual do registro através da intensidade.

(a)

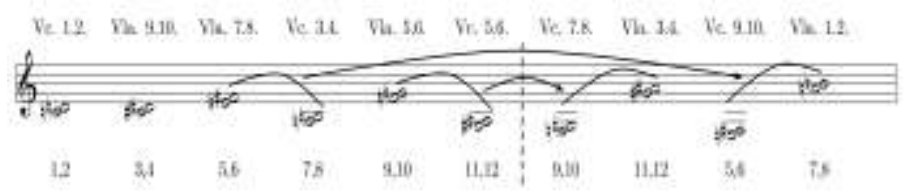

(b)
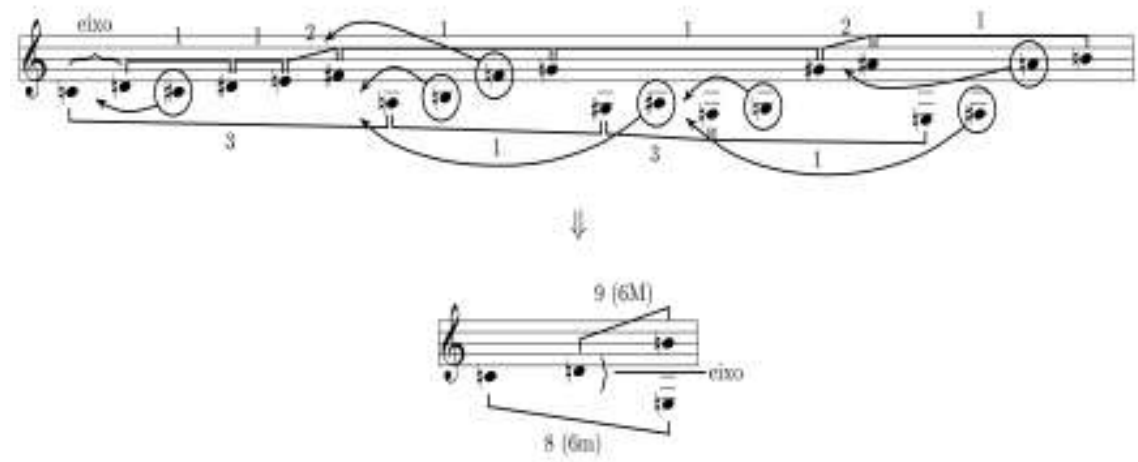

(c)

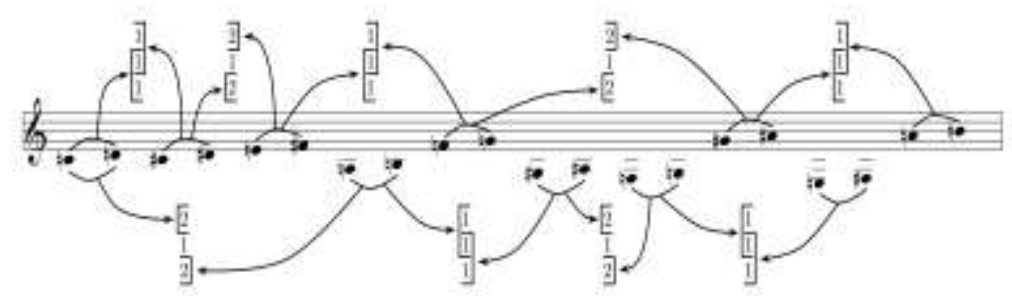


$\mathrm{Na}$ Figura 3 detalhamos o processo dos crescendi que acontece nos compassos 11, 12 e 13. Concretamente, escrevemos as alturas que são tocadas $f$ seguindo a ordem na qual aparecem na obra. As três partes da figura $(a, b, c)$ revelam aspectos diferentes de um mesmo processo. Em (a), mostramos as alturas agrupadas por pares como soam na obra indicando os instrumentos que as executam. Os números abaixo das alturas representam classes de altura. Observe-se que uma vez completado o total cromático com os violoncelos 5 e 6 se repetem algumas díades anteriores variando sua posição no registro; por exemplo, as notas realizadas pelos violoncelos 7 e 8, Fá3-Sol3, tinham aparecido nas violas 5 e 6 como Fá4-Sol4. Em (b), observamos que essas alturas tocadas $f$ seguem um percurso bastante claro e específico; as notas vão abrindo gradualmente o registro. Os números indicam os semitons existentes entre as notas que expandem o âmbito registral. Dentro dos círculos colocamos as alturas que preenchem algum intervalo anterior entre duas notas. Em (c), acrescentamos outra leitura sobre o processo descrito anteriormente, detalhando a forma como cada par novo de notas se relaciona com outro par anterior a partir da concatenação ou da proximidade mínima de semitom (os números também aqui indicam semitons).

Nesta parte da obra estão apenas as 10 violas e os 10 violoncelos tocando uma nota só por instrumento. Cada uma das 10 camadas do trecho é formada por duas notas em relação de segunda maior (esta agrupação das cordas por segunda maior já estava na primeira seção). A sequência de crescendi começa com os violoncelos 1 e 2 tocando a díade Dó-Ré, segue com as violas 9 e 10 tocando Dó\#-Ré\#, continua com as violas 7 e 8 executando Mi-Fá\#, e assim por diante, até acabar no compasso 13 com as violas 1 e 2 tocando Lá-Si. Veja-se a Figura 3 (a).

Nesta seção, a gradação adquire, pela primeira vez na obra, uma importância capital. Como pode ser observado na Figura 3 (b), as alturas colocadas em relevo através da intensidade seguem um percurso específico, delineando uma abertura gradual do registro. Esta gradação 
acontece dentro de um cluster estático ( $\mathrm{de} 8 \mathrm{j}+5 \mathrm{j}$ ) que não modifica realmente seu âmbito intervalar. Isto quer dizer que se estabelece um jogo sutil e ilusório com a percepção, sugerindo uma modificação que à rigor não existe (pois o registro não se modifica). Os crescendi, junto a um processo gradual de mascaramento, fazem com que esqueçamos por um instante do cluster originário $p p p$ e estabeleçamos, no seu lugar, o movimento expansivo das alturas. $O$ processo conduzido pela intensidade substitui a imobilidade do começo pela mobilidade e a direcionalidade. Isto representa um mascaramento duplo; um acústico e "real", causado pela intensidade e outro mais "ilusório", provocado pela direcionalidade própria dos crescendi.

Os crescendi, nesta seção (e sobretudo na seguinte, como veremos), não têm a função de enfatizar um momento determinado de uma melodia ou de um acorde como acontece, por exemplo, na música tonal. Não se trata de um elemento secundário utilizado para destacar outro elemento de importância maior. Longe disso, a intensidade passa a um primeiro plano; pois é a partir da intensidade, inclusive, que se modela o material. A intensidade gera a ilusão de estar ouvindo alturas novas, diferentes. Mais especificamente, temos a sensação de estar ouvindo um contraponto de alturas quando, na verdade, o contraponto é só de intensidades, pois as alturas permanecem sempre as mesmas (inclusive, vêm soando desde o começo da obra e continuarão soando na seção seguinte). Na Figura 4 pode ser observada esta ideia de um contraponto de intensidades ${ }^{10}$. Nesta figura mostramos os pares de notas em $f$ (a sequência de crescendi) tal qual surgem nos compassos $11-13$, ressaltando a presença de um contraponto de intensidades.

\footnotetext{
$10 \mathrm{O}$ trabalho com as intensidades neste trecho de Atmosphères constitui um antecedente claro do que acontecerá uns anos mais tarde, em 1968, na peça 1 de Dez peças para quinteto de sopros. Embora os casos não sejam evidentemente os mesmos, os crescendi por camadas e a ideia de um contraponto de intensidades que simula um contraponto de alturas será de capital importância na obra para sopros. Inclusive, o tempo lento, de semínima $=40$, será o mesmo.
} 
Figura 4. Atmosphères, c. 11-13, crescendi, contraponto de intensidades.

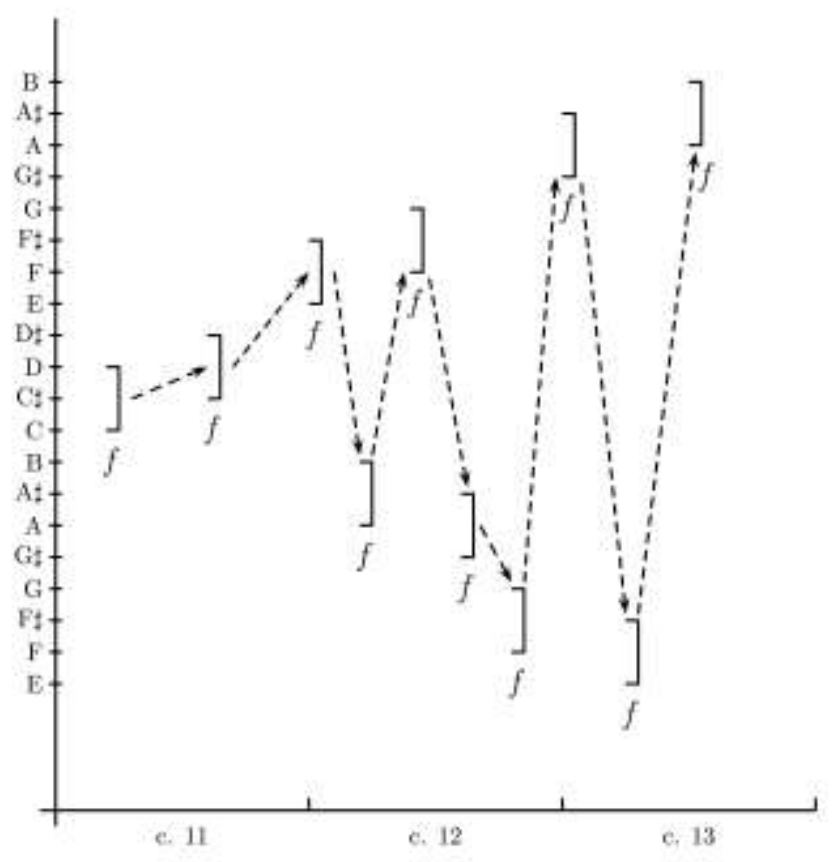

O movimento de abertura gradual do registro é acompanhado por uma gradação timbrística. Isto é, aos poucos são introduzidas algumas transformações no timbre das cordas que dão aos crescendi uma maior saliência na textura. Especificamente, se vai de uma sonoridade estática, ppp, senza colore, non vibrato, (compassos 9 e 10) para uma acumulação progressiva de $f$, poco a poco vibrato e finalmente poco a poco sul ponticello (compassos 11, 12 e 13).

A gradação é também utilizada como ferramenta para ligar os dois planos sutilmente presentes na seção A. Vejamos esta questão. Consideremos o cluster do começo da seção A como o plano de fundo e à sequência de alturas dos crescendi como o primeiro plano (siga-se o raciocínio com a Figura 3, b). A partir do estabelecimento das duas 
primeiras alturas, Dó-Ré (Vc. 1 e 2), as outras vão aparecendo em relação de proximidade. Isto é, Dó\#-Ré\# (Vla. 9 e 10) são próximas das alturas anteriores Dó-Ré, Mi-Fá\# (Vla. 7 e 8) são próximas de Dó\#-Ré\#, e assim por diante. As primeiras alturas (Dó-Ré) constituem as notas de referência para a ordenação posterior. Elas constituem o eixo a partir do qual as outras alturas são ordenadas, tanto para cima como para baixo. Como pode observar-se na Figura 3 (b), a abertura do registro é quase simétrica. Isto é, tomando a díade Dó-Ré como eixo, as notas finais da sequência mantêm quase a mesma distância com as notas-eixo (Si4 está a uma 6M de Ré4 e Mi3 está a uma $6 \mathrm{~m}$ de Dó4). Isto quer dizer que Ligeti opta por uma ordenação das alturas que permite gerar uma gradação entre um plano e outro. O plano dos crescendi alcança, de forma gradual e bastante equilibrada, o mesmo registro que o plano de fundo. Em outras palavras, tendo a totalidade como elemento anterior aos crescendi, se parte de uma acumulação progressiva que chega nessa mesma totalidade. Este gesto é ainda confirmado pela intensidade que vai de $p p p$ (cluster inicial) para o $f$ (sequência de crescendı) e volta para o $p p p$ (intensidade do plano de fundo que continua em $\mathrm{B}$ ).

Junto ao procedimento anteriormente descrito na sequência dos crescendi existe outra ordenação das alturas que vale a pena comentar. (A Figura 5 mostra mais claramente o processo simétrico que acontece nos crescendi a partir da concatenação de padrões de intervalos. Esta figura deve ser lida em relação com a Figura 3, c.) Dividindo o registro das alturas em duas metades, uma superior e uma inferior, podemos inferir que os processos de cima e de baixo podem ser entendidos a partir de uma simetria. Existe, a rigor, uma estrutura intervalar só que é transposta sobre diferentes alturas. Tomemos como exemplo a sequência Lá-Si-Dó-Ré. Sua estrutura intervalar, medida em semitons, é de 2-1-2. Na parte de cima, as primeiras notas são Dó-Ré. Este par se completa ao final da sequência com Lá-Si (isto é, Lá-Si-Dó-Ré; 2-1-2). Em segundo lugar, temos as notas Dó\#-Ré\#-Mi-Fá\#, ou seja, 2-1-2. No 
terceiro lugar, aparecem as notas Fá-Sol-Sol\#-Lá\# (2-1-2). Por último, como comentado, as notas Lá-Si completam o padrão com as notas do começo Dó-Ré. Veja-se, na Figura 5, o processo simétrico com as notas que ficam na metade inferior.

Figura 5. Atmosphères, c. 11-13, concatenação de padrões de intervalos na sequência de crescendi.

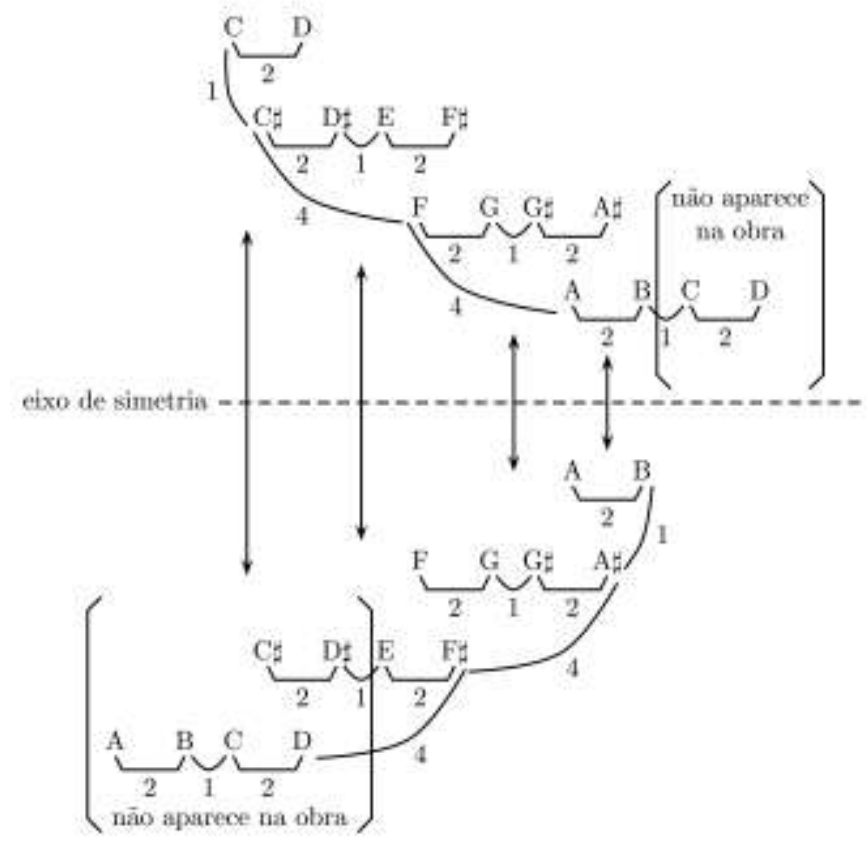

É interessante observar que os padrões são estruturados por concatenação começando sempre numa nota que não era tocada. Por exemplo, o padrão Dó\#-Ré\#-Mi-Fá\#, começa com Dó\#, isto é, a nota que falta no padrão anterior formado por Dó-Ré. O padrão Fá-Sol-Sol\#Lá\# começa com Fá, isto é, a nota ausente entre Mi e Fá\# anterior.

Este modo de estruturar o discurso nada mais é do que uma das possíveis formas de gerar o discurso com base na gradação. As notas são cuidadosamente encadeadas a partir de padrões que preenchem gradualmente um espaço cromático. A composição por concatenação 
aparece permanentemente na música de Ligeti e sob diferentes formas, pois ela constitui uma das principais formas da gradação. Ao concatenar os membros de um discurso estamos ligando um elemento (ou uma ideia) com o seguinte, de modo a evitar saltos. Ao concatenar, também estamos graduando, dosificando uma energia ou uma informação.

\section{Seção III (B): a gradação harmônica}

A seção III vai do fim do compasso 13 até o fim do compasso 22 , dura 55" e tem o mesmo tempo que as seções anteriores. A amplitude do registro vai de Mibl até Mi7, abarcando 6 oitavas $+2 \mathrm{~m}$. Trata-se, especificamente, de uma sonoridade formada por 59 vozes (cordas, madeiras e metais); um cluster cromático que vai de Láb2 até Mi7 (todas as alturas presentes) mais duas alturas no grave (Mibl e Mi1). Na Figura 6, mostramos: em (a), as alturas que aparecem na seção III com a respetiva instrumentação, e em (b), o cluster que resulta da superposição dessas alturas.

Figura 6. Atmosphères, c. 13-22, alturas e instrumentação.

(a)
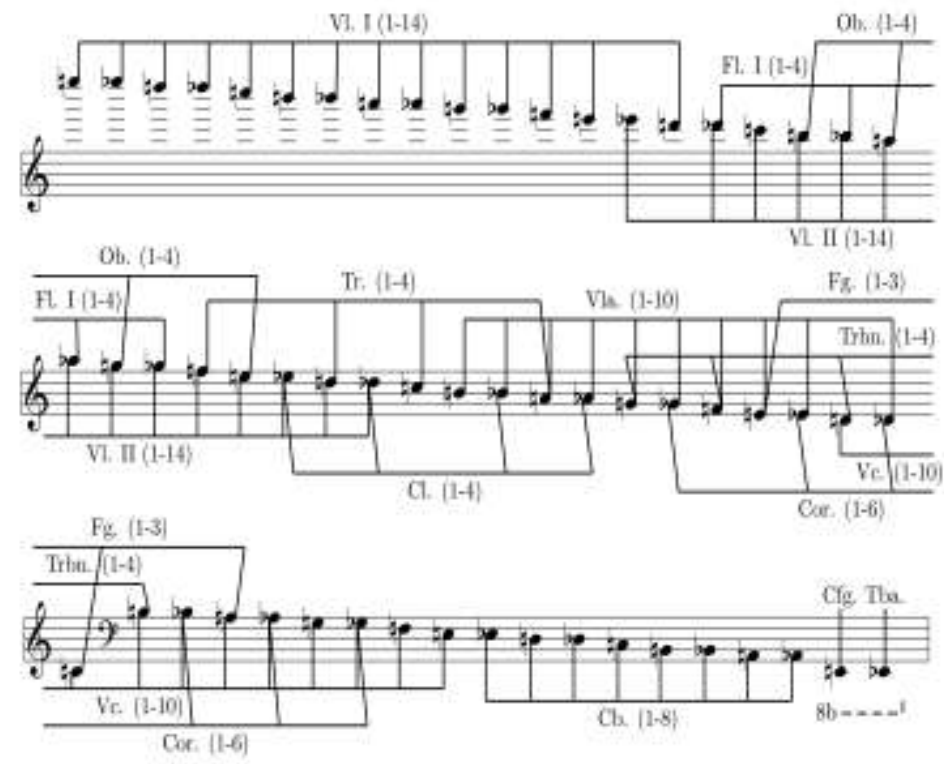
(b)

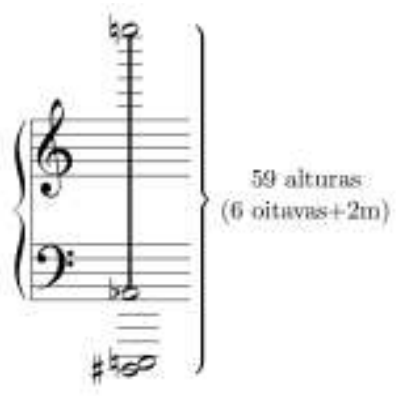

A sonoridade desta seção é modelada a partir da intensidade; os instrumentos tocam sempre as mesmas alturas e a atividade rítmica é praticamente nula. (Só as madeiras e os metais atacam mais de uma vez a mesma altura. Isto se deve à necessidade de respirar, não tendo nenhuma relevância do ponto de vista rítmico. Ligeti indica, na partitura, que esses ataques devem ser imperceptíveis.) Através de um jogo com crescendi e diminuendi se estabelecem modificações substanciais na percepção harmônica. A combinação de camadas harmônicas em crescendo com camadas em diminuendo produz a sensação de um movimento sutil entre planos sonoros. Este jogo faz com que sintamos que as transformações da textura nunca vêm de "fora" e sim de "dentro" do material. Vejamos em detalhe o modo como se desenvolve este processo.

Para gerar as transformações harmônicas, Ligeti parte de um pensamento composicional que pode ser comparado com a atitude de um escultor que elimina partes de uma matéria para chegar, depois de um certo processo, à forma final desejada. Como o escultor, Ligeti opera por subtração de partes de uma totalidade, neste caso representada pelo cluster cromático ${ }^{11}$.

11 Monjeau (2004, p. 120) relaciona a atitude de Ligeti com a ideia de Leonardo da Vinci segundo a qual a arte consiste em extrair partes de uma matéria que contém, em estado bruto, a forma final. 
Como comentado anteriormente, Ligeti constrói sempre de dentro para fora. A obra se modela a partir do contato com o material escolhido e nunca partindo de sistemas abstratos estranhos à própria concretude da obra. A atitude do compositor, nesta seção, é um reflexo claro dessa ideia.

A escala cromática (o cluster) constitui o material de alturas de base. O compositor observa que eliminando algumas notas dessa totalidade aparecem diferentes formações harmônicas. Nesse sentido, podemos observar que dentro da escala cromática existem diversas escalas e conjuntos de notas (escalas diatônicas e pentatônicas, modos, acordes, etc). Em outras palavras, a escala cromática constitui o conjunto maior que contêm vários subconjuntos.

Ligeti decide recortar a totalidade em duas partes. Dessa divisão resultam: a escala diatônica e a escala pentatônica. A segunda constitui o complemento da primeira pois juntando as duas obtemos o conjunto cromático de partida. Estes conjuntos de notas podem ser comparados às teclas brancas e às teclas pretas do piano. A escala pentatônica, por sua vez, está inclusa na escala diatônica; tomando a escala diatônica formada pelas teclas brancas do piano podemos notar que as notas RéMi-Sol-Lá-Si, por exemplo, formam uma escala pentatônica.

Juntando as alturas de oboés, fagotes (e contrafagote), trompetes e trombones obtemos a escala diatônica (teclas brancas do piano). Juntando as alturas de flautas, clarinetes, trompas e tuba formamos a escala pentatônica (teclas pretas do piano). Somando as notas das cordas obtemos a escala cromática (teclas brancas e pretas do piano).

Além dessa divisão, os grupos instrumentais apresentam diferenças e similitudes entre si. Por exemplo, flautas e oboés fazem uma escala pentatônica incompleta de quatro alturas. No entanto, as flautas tocam notas alteradas, Solb-Láb-Sib-Réb (sem Mib) e os oboés tocam notas sem alteração, Mi-Sol-Lá-Si (sem Ré). Vejam-se outras 
formações harmônicas na Figura 7, onde tornamos explícito o modo como se relacionam os conjuntos de notas utilizados em B.

Figura 7. Atmosphères, c. 13-22, relações entre conjuntos de notas.

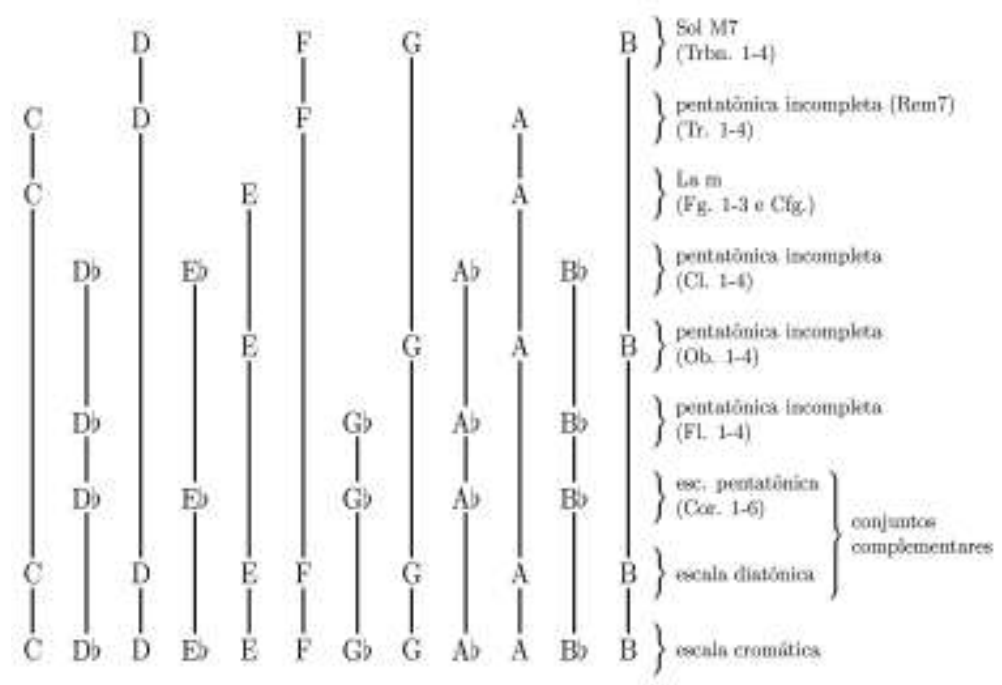

Em B, o processo harmônico pode ser resumido em quatro estágios. Cada estágio, por sua vez, está dividido em dois momentos (cada um desses momentos constitui a repetição da mesma escala). Antes de analisar isto vejamos alguns aspectos da Figura 8 que utilizaremos para estudar esta questão.

Na Figura 8 mostramos os planos sonoros que se originam em B a partir do trabalho com a intensidade (os crescendi e os diminuendi estão na parte de baixo da figura). Mostramos, especificamente, os momentos de cristalização de algum campo harmônico escrevendo as alturas tal como aparecem na obra.

No topo da figura indicamos os compassos onde surge cada plano harmônico e a formação escalar que o identifica: a = escala cromática, a1 = escala diatônica e a2 = escala pentatônica. As repetições 
da escala aparecem entre parêntesis. Como cada escala se repete duas vezes, fica a sequência seguinte: a-(a), a1-(a1), a2-(a2), a-(a).

Figura 8. Atmosphères, c. 13-22, planos harmônicos gerados a partir de crescendi e diminuendi.

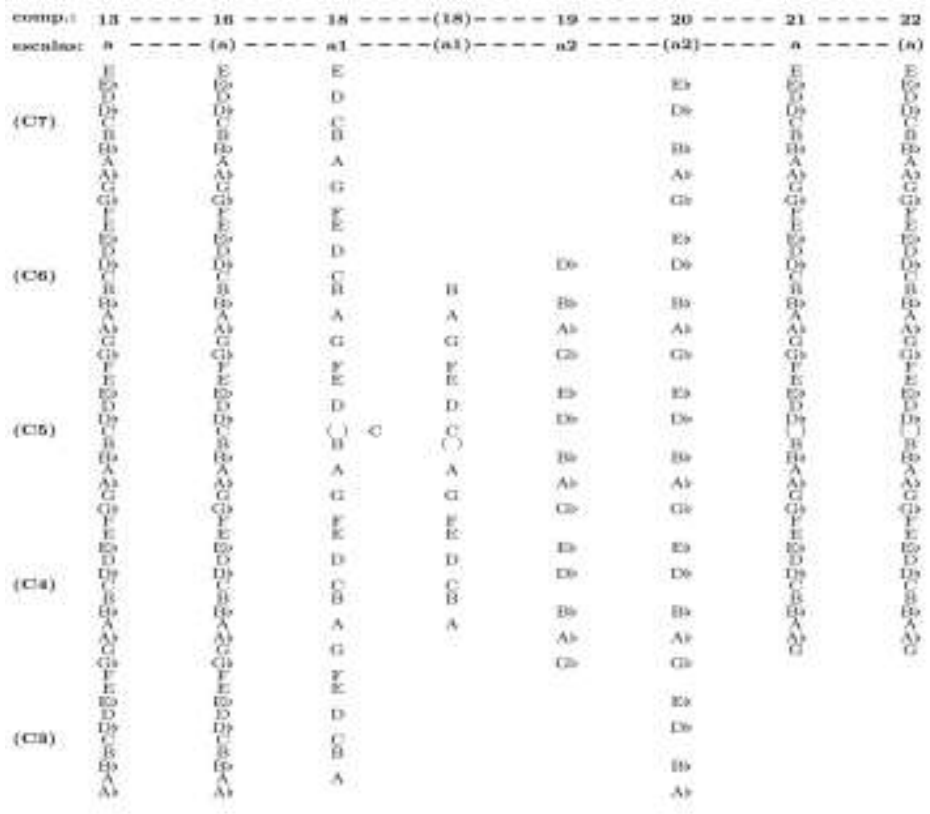

(C2)

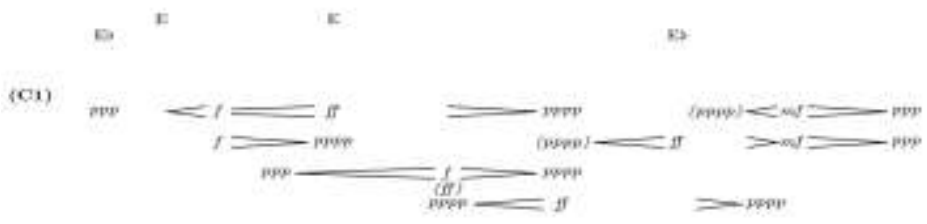

- $\quad$ Estágio 1: escala cromática.

a. Surge no final do compasso $13 \mathrm{com}$ o ataque de um cluster cromático pela orquestra, com intensidade $p p p$.

(a). A partir do compasso 15, as cordas começam um crescendo que chega até o $f$ no compasso 16 . 
- $\quad$ Estágio 2: escala diatônica.

a1. Se cristaliza no compasso 18 , mas aparece gradualmente a partir do $f$ do compasso 16. Nesse momento, as cordas se dividem em dois, realizando um percurso contrário que vai até o compasso 18. Uma metade continua crescendo e chega até $f f$, e a outra metade faz um diminuendo que chega até pppp. A metade das cordas que continua crescendo toca alturas sem alteração (teclas brancas do piano), e a metade que faz o diminuendo toca alturas com alteração (teclas pretas do piano). Por exemplo, os violinos I, 1 e 2, tocam Ré-Mi e crescem até ff e os violinos I, 3 e 4, tocam Réb-Mib e decrescem até pppp.

(a1). No final do compasso 17 começa outro crescendo nos oboés, nos fagotes, no contrafagote, nos trompetes e nos trombones que vai também até o compasso 18 . Esse crescendo chega um instante depois do $f f$ das cordas e gera uma nova cor na parte central do cluster diatônico (de Lá3 até Si5) que já estava soando. Esta sonoridade funciona como elemento de conexão com o estágio seguinte, tanto do ponto de vista da orquestração (o estágio seguinte começa com as flautas, os clarinetes e as trompas) como do ponto de vista harmônico (as estruturas harmônicas desses grupos instrumentais antecipam a estrutura pentatônica seguinte).

- $\quad$ Estágio 3: escala pentatônica.

a2. Neste estágio acontece o processo inverso em relação ao estágio anterior, subindo a intensidade do que estava pianissimo (escala pentatônica) e descendo a que estava fortissimo (escala diatônica). No compasso 18, oboés e fagotes deixam de tocar. Desse compasso até a metade do 19 há um crescendo e um diminuendo superpostos: o primeiro é realizado pelas flautas, os clarinetes e as trompas (de $p p p p$ para $f f$ nas flautas e nos clarinetes, e de $p p p p$ para $f$ nas trompas), e o 
segundo é executado pelos trompetes e trombones que tocam $f$, e pelas cordas que tocam $f f$ (todos decrescem para pppp) ${ }^{12}$.

(a2). A sonoridade pentatônica começa com os instrumentos de sopro e continua com as cordas, que realizam um crescendo (de $p p p p$ para ff) que vai da metade do compasso 19 até o começo do 20. Esse crescendo é acompanhado pelas trompas (que crescem de $f$ para $f f$ ) e pela tuba (que vai de $p p p p$ par $f$ ). Esta entrada das cordas gera a sensação de uma sonoridade mais forte não só pelo acréscimo de fontes sonoras mas pela ampliação do registro (em relação à amplitude intervalar dos instrumentos de sopro): o registro é ampliado uma nona maior para cima (de Réb6 para Mib7) e uma sétima menor para baixo (de Solb3 para Láb2). No compasso 20 , as flautas e os clarinetes fazem um diminuendo (de ff para pppp, morendo) e deixam de tocar. Nesse compasso, as trompas deixam de tocar abruptamente; a tuba desce subitamente para pppp e continua tocando até a metade do compasso 22 , junto com as cordas.

\section{- $\quad$ Estágio 4: escala cromática.}

a. A partir da metade do compasso 20 , um crescendo e um diminuendo superpostos vão até o fim do compasso 21 . As cordas que estavam tocando $f f$ (escala pentatônica) diminuem até $m f$ e as cordas que estavam tocando pppp (escala diatônica) sobem até $m f$. Como os dois grupos de cordas chegam à mesma intensidade, nenhum conjunto de notas se impõe sobre o outro. Disto resulta a volta para a escala cromática de partida (o cluster não é exatamente igual ao cluster do compasso 13, pois faltam as alturas graves que ficam abaixo do Sol3, e a nota Dó5 que era executada por um trombone que não toca desde o compasso 20 ).

12 Só o contrafagote passa subitamente de $f$ para $p p p$ (compasso 18). No entanto, ataca o $p p p$ de forma imperceptível e faz logo um diminuendo até $p p p p$, morendo. 
(a). A partir do $m f$, as cordas descem de forma conjunta para $p p p$ (no final do compasso 22).

O processo descrito anteriormente tem uma forte ligação com a ideia de gradação. Vejamos alguns exemplos.

1) Os planos harmônicos se estabelecem por meio da gradação. Nunca surgem abruptamente. A escala cromática do primeiro estágio constitui a totalidade de partida que é desmembrada progressivamente no decorrer de B. A escala diatônica do segundo estágio aparece como resultado da subtração gradual da escala pentatônica a partir da intensidade (a1). A escala pentatônica do terceiro estágio é o resultado de um processo gradual duplo: o ascenso da escala pentatônica para o primeiro plano e o descenso da escala diatônica para o segundo plano (a2). Finalmente, a escala cromática do quarto estágio se constitui como consequência de um processo de convergência gradual das escalas diatônica e pentatônica (a).

Analisemos mais em detalhe as transições do estágio 2 para o estágio 3 e do estágio 3 para o estágio 4 (veja-se a Figura 9, onde mostramos as gradações harmônicas entre planos sonoros que acontecem nos compassos 18-21).

Figura 9. Atmosphères, c. 18-21, gradações entre planos harmônicos.

Parte 1

(a)

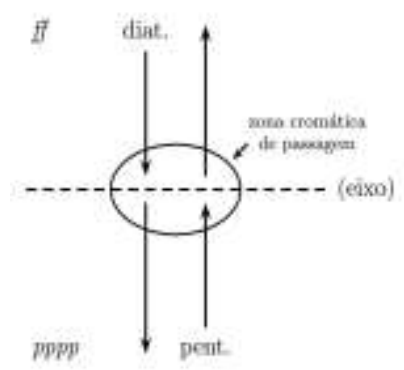

(b)

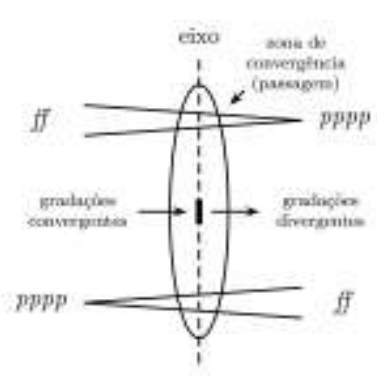


Parte 2

(a)

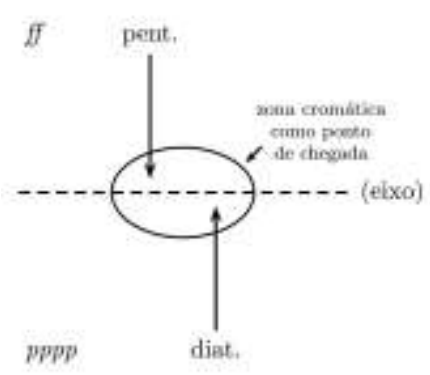

(b)

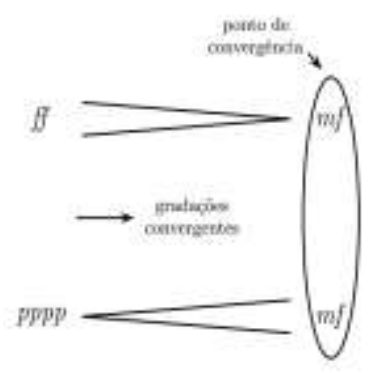

Parte 1: c. 18-19; passagem do diatônico para o pentatônico, de (a1) para a2. Parte 2: c. 20-21; passagem do pentatônico para o cromático, de (a2) para a.

$\mathrm{Na}$ passagem do diatônico para o pentatônico, de (a1) para a2, nos compassos 18-19, o que estava pianissimo sobe para fortissimo (escala pentatônica), e o que estava fortissimo desce para pianissimo (escala diatônica). Esta gradação faz pensar que se os dois planos harmônicos se deslocam progressivamente existe um ponto, ou uma zona, no meio do percurso onde os dois planos se fundem. Mais precisamente, se num ponto médio (eixo) os dois planos atingem a mesma intensidade, a escala resultante será, nesse momento, a cromática. Em outras palavras, as gradações são convergentes no ponto médio do percurso e divergentes a partir daí. Como o processo não dura mais do que 3 segundos, a zona de confluência é pouco perceptível (note-se que um processo de gradação muito mais demorado tornaria claramente audível essa zona cromática). Perceptivamente, temos a sensação de uma harmonia que se opaca primeiro e se torna mais consoante depois. Este tipo de trabalho com gradações opostas faz com que para passar de um estado harmônico para outro se passe pelo estado de partida. Isto é, não se passa linearmente do diatônico para o 
pentatônico como se um piano executasse um acorde e logo outro. Antes, o avanço passa previamente por um retrocesso. Este retrocesso para a totalidade de partida, como comentado, não é mais do que uma consequência da relação de complementariedade harmônica de ambas as gradações; escala diatônica (teclas brancas) e escala pentatônica (teclas pretas) são conjuntos complementares que somados formam o conjunto da escala cromática.

Frequentemente, os procedimentos composicionais utilizados por Ligeti sobre vários parâmetros ou aspectos da obra são estruturados com base na ideia de avançar não linearmente, mas recuando algum passo para depois continuar avançando. Isto torna o discurso mais gradual fazendo com que a novidade seja sempre rigorosamente administrada.

No último estágio, que diz respeito à passagem do pentatônico para o cromático, de (a2) para a, nos compassos 20-21, tanto o que estava fortissimo como o que estava pianissimo vão para o mezzo-forte. Este caso pode ser pensado como a metade do processo anteriormente comentado (isto é, a parte 1 da Figura 9). As gradações se detêm no ponto de convergência e, portanto, se fundem num elemento só. O $\mathrm{mf}$ poderia ter sido o ponto meio do processo e as gradações ter continuado seus percursos, crescendo uma e decrescendo a outra, até se estabelecerem em lugares opostos do processo. No entanto, ao se deterem, deixam de existir como elementos diferenciados e passam a ser parte de uma nova entidade.

Nos exemplos anteriores vêm à tona dois conceitos: o de direcionalidade e o de simetria. Podemos dizer que os processos comentados acima são direcionais pois existe uma direção, um movimento que vai de um ponto para outro. Por outro lado, esses processos ficam ordenados em torno de um eixo de simetria formado pela soma dos dois elementos. A escala cromática constitui o ponto de convergência entre as duas gradações. Quando cada plano está num extremo (fortissimo um e pianissimo o outro) ouvimos o mais forte e o 
outro fica como plano de fundo. Uma vez começadas a gradações contrárias, o processo pode ser compreendido em torno da distância que estabelecem com o eixo de simetria (veja-se a Figura 9).

2) Na seção III, existe outro nível em que a gradação é estrutural e que diz respeito aos aspectos formais. Nesse sentido, podemos dizer que do estágio 1 até o estágio 4 os diferentes elementos são dispostos de tal forma que aparece uma gradação ascendente com seu ponto climático no estágio 3 e logo depois uma gradação descendente até o fim de B. Esta última gradação fecha sutilmente a seção na forma de arco (tipo ABA). Vejamos esta questão seguindo a série de passos que conformam a gradação.

\section{- $\quad$ Estágio 1.}

a. Se parte de uma sonoridade cromática $p p p$ similar à do começo da obra.

(a). Se adiciona o crescendo até $f$ nas cordas mantendo a harmonia cromática do começo.

\section{- $\quad$ Estágio 2 .}

a1. Aparece a gradação harmônica. O material de alturas anterior constitui uma espécie de totalidade sem gradações. Como a pedra bruta do escultor, o cluster cromático do começo da seção contém as gradações ainda em potência. Com a aparição da escala diatônica aparece a primeira gradação do material de alturas. (a1). Se reafirma o passo anterior dado pelas cordas a partir do crescendo nos instrumentos de sopro (lembre-se que até agora só as cordas tinham tido, em B, uma atuação importante e que, portanto, a entrada em fortissimo dos sopros constitui uma novidade). 


\section{- $\quad$ Estágio 3.}

a2. Se avança um degrau no que diz respeito à estrutura harmônica. Aparece uma formação mais consoante, a escala pentatônica.

(a2). Se amplia o registro com base na mesma harmonia. Este ponto constitui o momento de climax da seção e o ponto de maior distância (harmônica e expressiva) em relação ao ponto de partida. A presença das cordas funciona como conexão com o estágio seguinte formado exclusivamente pelas cordas (a tuba toca pppp).

- $\quad$ Estágio 4.

a. Se volta para a escala cromática do começo da seção, indo gradualmente para a mesma intensidade. O regresso para o cluster cromático representa também o regresso para o material sem gradações.

(a). Se repete o mesmo cluster, mas se diminui progressivamente a intensidade, de $m f$ para $p p p$.

No processo descrito anteriormente, podemos observar também a presença dos conceitos de direcionalidade e simetria. A direcionalidade se manifesta no ordenamento dos materiais que respondem a uma estrutura de gradação. A simetria deve ser pensada de modo mais genérico: existem dois elementos similares nos extremos, sem gradação, e uma zona de gradações harmônicas no meio. A saída e a volta para o cluster cromático acontece em forma de espelho. Se sai por gradações divergentes e se volta por gradações convergentes. Em termos gerais, isto adquire a forma de um grande crescendo seguido de sua forma espelhada, um diminuendo.

A seção B traz à tona uma forma de pensar o material musical que será desenvolvida em obras posteriores do compositor, como Lux aeterna (1966), Lontano (1967), o Segundo Quarteto de cordas (1968) ou Ramifications (1968-9). Nestas obras, o cluster será utilizado cada vez mais como ponto de partida (ou de referência) e não como fim da 
composição. As notas, que na seção B se ouvem muito pouco por causa do jogo com as intensidades (gradações de intensidade contrárias), nas obras posteriores estarão ausentes, formando clusters com buracos ou harmonias híbridas (a meio caminho entre uma configuração harmônica e outra). O cluster, no entanto, será ainda, em todas essas músicas, o material de base a ser modelado, esculpido.

\section{Referências}

COELHO DE SOUZA, Rodolfo. Uma introdução às teorias analíticas da música atonal. In: Rogério Budasz (Org.), Pesquisa em música no Brasil: métodos, domínios, perspectivas, p. 122-153. Goiânia: ANPPOM, 2009.

DUBOIS, Jean. Dicionário de Lingüística. São Paulo: Cultrix, 2011.

ETKIN, Mariano; CANCIÁN, Germán; MASTROPIETRO, Carlos; VILLANUEVA, María Cecilia. Superposición y gradualidad en "Hallowe'en" de Charles Ives. La Plata: Editorial de la Universidad Nacional de La Plata, 2000.

FONTANIER, Pierre. Les figures du discours. Paris: Flammarion, 1977.

HINDEMITH, Paul. The craft of musical composition. Volumes 1 e 2. Mainz: Schott, 1970.

LIGETI, György. Atmosphères. Viena: Universal Edition, 1961.

MOISÉS, Massaud. Dicionário de termos literários. São Paulo: Cultrix, 2004.

MOLINIÉ, Georges. Dictionnaire de rhétorique. Paris: Librairie Générale Française, 1992.

MONJEAU, Federico. La invención musical: ideas de historia, forma y representación. Buenos Aires: Paidós, 2004.

POE, Edgar Allan. The philosophy of composition. Graham's Magazine, v. 28, n. 4, p. 163-167, 1846.

SAPIR, Edward. Grading: a study in semantics. In: David G. Mandelbaum, (Ed.), Selected writings of Edward Sapir in language, culture and personality, p. 122149. Berkeley: University of California Press, 1949.

VITALE, Claudio. A gradação nas obras de György Ligeti dos anos sessenta. Tese de doutorado, ECA, USP, 2013.

WONG, Wicius. Fundamentos del diseño. México: Gustavo Gili, 1995. 